\title{
Drought stress patterns in Italy using agro-climatic indicators
}

\author{
Nazzareno Diodato', Gianni Bellocchi ${ }^{2, *}$ \\ ${ }^{1}$ Monte Pino Met Research Observatory, GTOS/TEMS Network - Terrestrial Ecosystem Monitoring Sites, \\ Contrada Monte Pino, 82100 Benevento, Italy \\ ${ }^{2}$ Agrichiana Farming, Montepulciano, Via di Sciarti n. 33/A, 53040 Siena, Italy
}

\begin{abstract}
This paper examines the drought patterns in Italy for the period from 1961 to 2006. The condition of drought was considered from an agricultural perspective, using the variability in the annual yield of maize as an indication of climate patterns. A procedure is presented where weather datasets, a drought stress index (MCDI: Mediterranean crop drought index) and geo-spatial analysis are used to assess the spatial distribution and the general evolution of drought. The regional perspective presented characterizes the general climatology of Italy and compares the climate to a severe drought that occurred in 2003. This study identifies some areas (such as major islands, the central Tyrrhenian coast and south-eastern zones) where agricultural drought is likely to be a problem. In general, the temporal patterns outlined in this study indicate an increase in drought over Italy. Considering the poor resolution of global output results for regional and sub-regional assessments, the analysis carried out provides background data and a methodology for climatologists, ecologists and others interested in developing bio-climate patterns within large geographical regions.
\end{abstract}

KEY WORDS: Climate change - Drought · Italy · Mediterranean crop drought index pattern · Geo-spatial analysis · Temporal analysis

Resale or republication not permitted without written consent of the publisher

\section{INTRODUCTION}

Ecosystem responses to future climate change and the likely impact of the response of plants to such changes have been widely analysed (Easterling et al. 2000, Füssel \& van Minnen 2001, Meir et al. 2006). However, only recently has evidence of the observed effects of climate change on crop production been addressed and reported (Lobell \& Asner 2003, Chmielewski et al. 2004, Tao et al. 2006). In this context, drought has received special attention, since it was regarded as having been the most serious climatic risk in the 20th century, responsible for the loss of billions of U.S. dollars (Bruce 1994). Drought is considered to be an extreme climatic event, which varies in severity, duration and magnitude across all continents, causing critical damage to both the natural environment and human lives (e.g. Min et al. 2003, Modarres 2007). Climate models point to a future exacerbation in drought related to an increase in the frequency of severe heat wave episodes (Beniston \& Stephenson 2004). However, drought is generally identified by a variety of climate elements, where precipitation plays an important role in natural and managed environments (Tao et al. 2006). For the Mediterranean basin, precipitation is expected to decrease in the future (New et al. 2002), and, if the projections are met, the regional consequences will be severe, owing to the scarcity of water resources in this area, the high demand through human activities, and erosion and desertification processes. However, global climatic models have limitations because of their scale resolution, and the model output patterns of drought may not be consistent for areas with high precipitation variability, such as Mediterranean climate areas (Vicente-Serrano et al. 2004). Heat waves and droughts are common features of Mediterranean/ European climate and have a massive, negative impact on growth in ecosystems (Mavromatis 2007). However, rainfall deficiencies in summer and winter can have different hydrological impacts depending on the pre- 
ceding levels of storage. Historical droughts were analysed by Thomsen (1993) at selected European stations for the period from 1750 to 1989 ; results were that both types (summer and winter) can occur, encompass large areas and persist for several years, although dry winter and spring seasons were less frequent during both the 18th and 19th centuries throughout the Mediterranean (Pauling \& Paeth 2006, Diodato 2007). More recent paleoclimatic reconstructions for Europe (Masson-Delmotte et al. 2005) indicate that, when climate changes from cooling to warming, the frequency of extremely dry years is doubled. This was also found by Beniston \& Stephenson (2004), indicating that extreme drought events are becoming more frequent. In this context, drought is currently an environmental problem afflicting Mediterranean and European ecosystems with ever increasing importance (Conedera et al. 2003). The effect of droughts may be of regional or continental concern, including the decrease of precipitation and soil moisture or the increase of crop yield variability and reduction in suitable areas for traditional cultivations (Olesen \& Bindi 2002). In the last decades, yield losses from drought events have significantly increased in Europe, which suggests trends towards both increasing vulnerability in some regions (Lloyd-Hughes \& Saunders 2002) and increasing length of dry spells (Klein Tank \& Konnen 2003).

The analysis of moisture extremes across Europe (Briffa et al. 1994) showed strong decadal-scale variability in dry-spell frequency. Although drought can be important in a sequence of years with rainfall deficiency, the heat wave and extreme drought that hit Europe in 2003 were driven by an extraordinary extension of the subtropical anticyclone for some months, during which hot, dry air was conveyed northward from the southern Mediterranean (Luterbacher et al. 2004, Rebetez et al. 2006). During this event, temperatures of 35 to $40^{\circ} \mathrm{C}$ were repeatedly recorded in July and, to a larger extent, in August in many European countries (including Italy), drastically raising evapotranspiration rates. Managing drought continues to be a big issue, in spite of improvements in crop and livestock breeding, irrigation systems, tillage practices, and new or emerging technologies, and it demands more research and development on drought mitigation measures (Wilhite 2000). Case studies recently reported for the Mediterranean area have indeed demonstrated that extended periods of drought stress still continue to result in significant impacts on agricultural production (Perini \& Beltrano 2004). In environments with high spatial and temporal variability of precipitation, it is reasonable to expect the same variability in droughts (e.g. Fowler \& Kilsby 2002). Peninsular Italy and its islands are particularly suitable for drought and heat wave analysis (Baldi et al. 2006).
The interpretation of drought-induced plant stress is a focus of the present paper. Several indices have been developed over the years that estimate the severity of drought (Loomis \& Connor 1992). They basically assume that a large accumulation of heat during a given time frame (e.g. decade, season, month), associated with a large deficiency in rainfall during the same time frame, will result in great plant stress. The Palmer Drought Index (Palmer 1965) was often used to characterize drought in many parts of the world, and its use is interesting because it considers both precipitation and evapotranspiration. However, since it requires a number of somewhat restrictive assumptions (Alley 1984), simpler indices have also been used to characterize potential plant stress (e.g. Gage \& Mukerji 1977).

Several approaches have been developed to evaluate the spatial and temporal patterns of drought-stress conditions (see Gathara et al. 2002 for a synthesis), from remote-sensed data (Ghosh 1997) to surface data (Hisdal et al. 2001, Wilhelmi et al. 2002), or from both types of data (Vogt et al. 2000). However, none of these methods is consistent and reliable (Fowler \& Kilsby 2002). The conversion of remote sensing data into useful information for drought detection and monitoring requires a good understanding of the physics of the measurements as well as sophisticated analysis tools (Vogt et al. 2000). Conversely, surface climatic measurements are readily usable, but their limited spatial density poses difficulties in the interpretation of results. To overcome this problem we studied the spatial variability and temporal patterns of drought across Italy, using a long-term database of agricultural production and weather records, and an indicator of agricultural drought stress. Maps of the drought indicator, integrated with crop yield and vegetation greenness, were generated for Italy using the inverse weighed distance interpolator (driven by an explorative geostatistical analysis). The analysis was performed using maize Zea mais L. - a crop that was well fitted to the Mediterranean region and central to the Italian economy - to gather information on water stress situations. For drought characterization, annual grain yield of maize was chosen, as it is a singular representation of the culmination of diverse biophysical processes.

The present paper is structured into 4 sections. In Section 2, we present the study area, the database, and the methods for temporal and spatial analyses. In Section 3, the temporal and spatial drought patterns are shown and long-term climate dynamics are investigated. Possible consequences on crop productivity of drought patterns at regional levels are also discussed. Finally, remarks are made concerning the bearing of the findings on a wider interpretation of drought phenomena and the need for future studies. 


\section{STUDY AREA AND METHODS}

\subsection{Study area}

Italy is centrally located in the Mediterranean basin and comprises an area of about $301000 \mathrm{~km}^{2}$ between 36 and $47^{\circ} \mathrm{N}$ (Fig. 1). For the purpose of this study, a subregional classification was adopted between northern $\left(\sim 44\right.$ to $\left.47^{\circ} \mathrm{N}\right)$, central $\left(\sim 41\right.$ to $\left.44^{\circ} \mathrm{N}\right)$ and southern $(\sim 36$ to $\left.41^{\circ} \mathrm{N}\right)$ Italy. The yearly mean air temperature is $\sim 13^{\circ} \mathrm{C}$ (from about $8^{\circ} \mathrm{C}$ in the north to $16^{\circ} \mathrm{C}$ in the south), and the mean annual rainfall values are between $<500$ and $\sim 1500 \mathrm{~mm}$, roughly decreasing from north to south, but following complex spatial and temporal patterns. The area is, in fact, characterized by a heterogeneous mix of geographic systems (peninsular shape, Alps chain in the north, Apennines chain all along the peninsula). Such heterogeneity affects mesoscale circulation and generates greatly varying precipitation (Meneguzzo et al. 1996) and evapotranspiration (Diodato \& Bellocchi 2007) patterns at all spatial and temporal scales. In summer, long periods of bright sun can be associated with hemispheric circulation from the south (i.e. sub-tropical anticyclones), often interrupted by atmospheric instability with showers and thunderstorms.

Weather has an important impact on Italian agricultural activity, which plays an essential role in the ecology and economy of the country. Domestic crop production comprises a significant proportion of the national food supply and by-products, as well as a component of the nation's export marketing strategy. The role of weather as a cause of the variability of crop production at local and national scales is therefore a subject of concern. Variability in the annual yield of

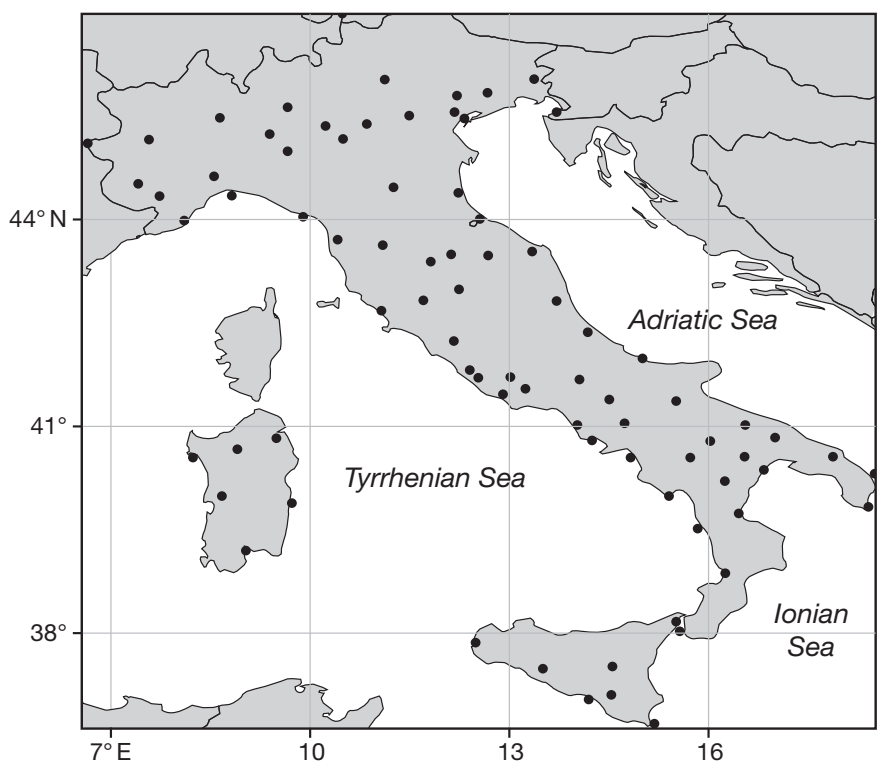

Fig. 1. Distribution of station data points in Italy crops (especially for non-irrigated cultivations) is a useful indicator of regional climate patterns because plant growth and biomass accumulation have been found to depend primarily on weather (e.g. Gage 2003). The Italian climate is usually defined as mildtemperate, although in recent years the climate has often deviated from this type towards either an excess of rainy months or more arid seasons. In the period from May to September, rainfall amounts are generally slight, with long periods of drought stress in mid- and late-summer, when the maximum temperatures frequently exceed $30^{\circ} \mathrm{C}$. As a consequence, the soil moisture reserve declines. Water storage is the most limiting factor for crop yields, causing varying levels of crop stress, contingent on the developmental stage of the plant. An example of this was the extraordinary heat wave that occurred in 2003 throughout Europe, which was associated with deficit soil moisture and extreme drought stress. In particular, for the period from May to August 2003, the temperature anomaly registered throughout Europe was considerably above normal (1961 to 1990) values of 2 to $4^{\circ} \mathrm{C}$ (www.ncdc.noaa.gov/ oa/climate/research/2003/ann/global.html).

\subsection{Database description}

A database of annual maize grain yields and climate data (monthly values of precipitation and minimum and maximum temperatures, then aggregated on monthly basis) was compiled from public web sources supplied, respectively, by ISTAT (www.istat.it) and the system SCIA (www.scia.sinanet.apat.it) of the APAT (Italian National Agency for Environmental Protection, www. apat.gov.it). The SCIA database is based on information from different weather networks: Italian Air Force Meteorological Service (www.meteoam.it), UCEA-BDAN (www.ucea.it) and other local networks. SCIA weather data were available for individual weather stations from 1961 to 2006. The climate datasets were downloaded from primitive data points not uniformly distributed in time and space. For this reason, a minimum number of stations (81), common to a long-term climate dataset - 1961 to 1990 (baseline) - and next to this period for individual years, were taken for this study (Fig. 1). For analyses on a yearly basis, since 1961, a homogeneous dataset was only available on a $\sim 1 \times 1^{\circ}$ grid, supplied by the Goddard Institute for Space Studies (www.giss.nasa.gov). Weather data from other recent years were used for a more complete temporal analysis in 2 test areas: the Lombardy region (northern Italy) and Benevento province (southern Italy).

For each Italian province, ISTAT supplied average maize yields for 1961 to 1990 and annual yields for 1999 to 2006 (public web source). For 2 test areas 
(Lombardy region and Benevento province), annual yields were also retrieved for antecedent years (1992 to 1998) from ISTAT bulletins.

\subsection{Geo-processing}

Climate and maize yield patterns were comparatively assessed, as associated with the measurements taken at the meteorological sites. To scale the climate data to ecological regions, each of the ecological categories (roughly reflected by the administrative provinces) was associated with each of the data points in the Italian domain. Weather and crop data points did not match exactly. Crop data for the provincial territory were centrally placed in each province, and associated to the closest available station. Both climate and yield databases were retrieved from the public web domain to describe average conditions for a $30 \mathrm{yr}$ reference period from 1961 to 1990 (climate baseline) and for individual years (from 1961 to 2000). Both climate and yield datasets were imported by a GIS system (ArcGIS-ESRI, www.esri.com) and processed to generate equal grid-cells of output (pixel size equal to $30 \mathrm{~km}$ ) for successive manipulation, computation and interpretation. The final map made by geo-processing permits the linkage of crop yield and monthly drought index values to gain knowledge about temporal and spatial characteristics of crop yield and the effects of climate on crop production-regulating patterns.

Satellite-derived maps of an indicator of the state and productivity of vegetation in Italy, FAPAR (fraction of absorbed photosynthetically active radiation), were downloaded (http://fapar.jrc.it) and used to relate the response of drought events to the vegetation patterns.

\subsection{Drought assessment using stress indices}

Drought was analysed using a crop drought stress index developed for potential use in Mediterranean areas, termed Mediterranean crop drought index (MCDI). This index, derived from temperature and precipitation data, was compared to 2 relatively simple drought stress indices, which, to some extent, share the same type of inputs: Ulanova's index (Gathara et al. 2002) and the heat/precipitation ratio (HPR) (Gage \& Mukerji 1977). Both these indices avoid the need for continuous evapotranspiration inputs that are not observed (or difficult to estimate) for a large number of stations over a long period of time.

The Ulanova's index $\left(C_{\mathrm{y}}\right)$ is a generic crop drought stress index, formulated as follows:

$$
C_{\mathrm{y}}=\frac{0.01 \sum T_{\text {May-June }}}{W_{\mathrm{a}}+\sum p_{\text {May-June }}}
$$

where $T_{\text {May-June }}\left({ }^{\circ} \mathrm{C}\right)$ is the sum of mean air temperatures for May and June, $p_{\text {May-June }}(\mathrm{mm})$ is the sum of precipitation for May and June, and $W_{\mathrm{a}}(\mathrm{mm})$ is the usable soil moisture reserve at $1 \mathrm{~m}$ depth when the average daily spring air temperature exceeds $5^{\circ} \mathrm{C}$ (climatological value supplied for each site by Perini et al. 2004).

The HPR, originally developed for interpretation of drought-induced stress in insect populations (Gage \& Mukerji 1977) and later applied to maize (Gage 2003), is as follows:

$$
\mathrm{HPR}=\frac{\mathrm{MDD}_{m}}{1+p_{m}}
$$

where $\mathrm{MDD}_{\mathrm{m}}$ is the degree-day accumulation in the month $m$ and $p_{m}(\mathrm{~mm})$ is the precipitation in the month $m$. High HPR values indicate that heat accumulations are associated with low amounts of precipitation.

Since the response of yield throughout the growing season is dependent on the environmental conditions occurring in the growing month, as well as the conditions occurring in antecedent periods (Wu \& Wilhite 2004), $C_{\mathrm{y}}$ and HPR were revised to give the monthly based MCDI such that:

$$
\mathrm{MCDI}=\frac{\mathrm{MDD}_{m}}{0.55 p_{m-1}+p_{m}+30}
$$

For both Eqs. (2) \& (3), degree-day accumulation was calculated following the single triangle method (after Snyder 2002):

$$
\begin{gathered}
\mathrm{MDD}_{m}=n\left[\frac{\left(T_{\max }-T_{\mathrm{L}}\right)^{2}}{24}+\left(T_{\min }-T_{\mathrm{L}}\right)\right] \quad \text { if } T_{\mathrm{L}}<T_{\min } \\
\mathrm{MDD}_{m}=n \frac{\left(T_{\max }-T_{\mathrm{L}}\right)^{2}}{24} \quad \text { if } T_{\mathrm{L}} \geq T_{\min }
\end{gathered}
$$

where $T_{\max }$ and $T_{\min }$ are the monthly mean maximum and minimum air temperatures $\left({ }^{\circ} \mathrm{C}\right)$, respectively; $T_{\mathrm{L}}$ is the threshold temperature, which was set equal to $10^{\circ} \mathrm{C}$ for maize; and $n$ is the number of days in a month.

Scatterplots and linear fits of data in Fig. 2 show a high degree of correlation $\left(\mathrm{R}^{2}=0.65\right)$ between MCDI and maize yield, while a poor fit was observed with both other indices. The terms of Eq. (3) are therefore a combination of concepts that make MCDI more operational than other indices in the face of the relationship between drought and maize yields.

\subsection{Geo-spatial analysis of drought}

An approach that calculates the MCDI values at any unsampled location from the neighbourhood data is the interpolator called the inverse weighted distance (IWD). This method combines the proximity concept with the gradual change of the trend surface. The underlying assumption is that the value of an attribute 

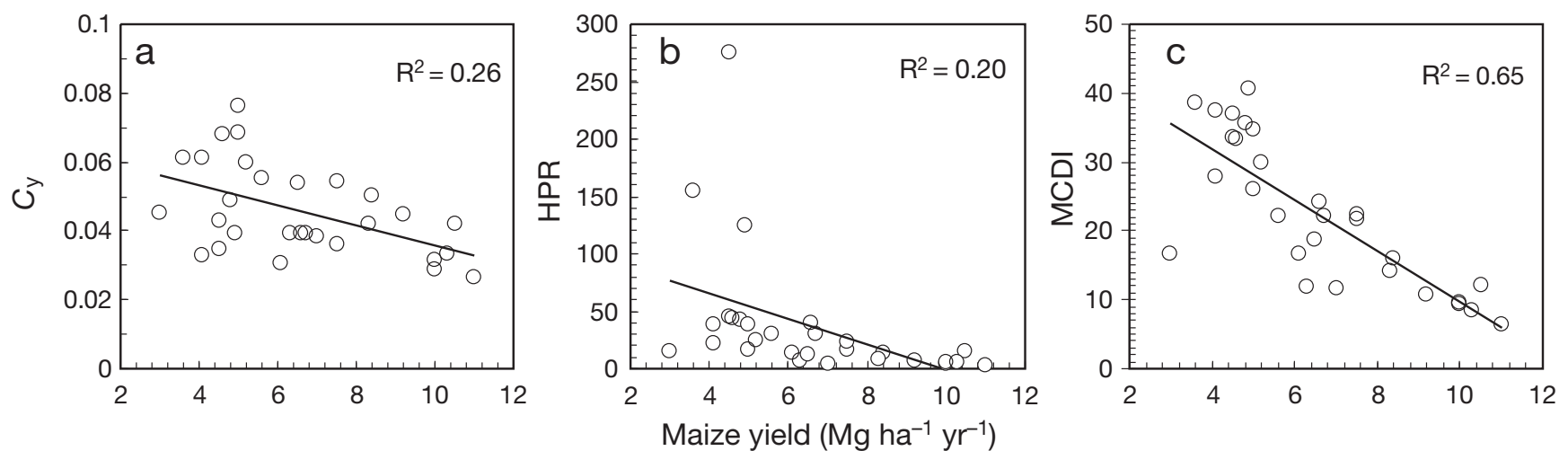

Fig. 2. Relation between drought indices and maize yield in the period from 1999 to 2006 for non-irrigated maize crops in Italy with (a) Ulanova's index $\left(C_{\mathrm{y}}\right)$, (b) the heat precipitation ratio (HPR) and (c) the Mediterranean crop drought index (MCDI). HPR and MCDI were accumulated from May to August

$z$ at some unvisited points is a distance-weighted average of data points occurring within a neighbourhood or a window surrounding the unknown point. The form of the inverse distance weighting estimator, $Z_{\text {IWD }}^{*}\left(s_{0}\right)$, is:

$$
Z^{*}{ }_{\mathrm{IWD}}\left(\boldsymbol{s}_{\mathrm{o}}\right)=\frac{\sum_{i=1}^{n(\boldsymbol{s})} z\left(\boldsymbol{s}_{i}\right) \times d_{i}^{-W}}{\sum_{i=1}^{n(\boldsymbol{s})} d_{i}^{-W}}
$$

where $z\left(\boldsymbol{s}_{i}\right)$ are the station-location data points, $d_{i}$ are the distances between the station-location combinations $\boldsymbol{s}_{i}$ and the unknown point $\boldsymbol{s}_{0}$, and $w$ is the weight involved in the geospatial interpolator calibration IWD. All computations were carried out by using the Geostatistical and Spatial Analyst modules implemented in ArcGIS-ESRI (Johnston et al. 2001).

\section{RESULTS AND DISCUSSION}

\subsection{Temporal pattern of maize yield}

Variability in maize yield over time (1992 to 2006) is shown in Fig. 3 at 2 selected areas of Italy (1 in the north: Lombardy region, Panel (a); 1 in the south: Benevento province, Panel (b). The seasonal MCDI (accumulated from May to August) is also reported for the same period. At both sites, general trends towards increasing or decreasing yields are assumed not to be associated with changes in technology (L. Mariani, University of Milan, pers. comm.). For maize yield in Italy, trends associated with plant breeding can be considered to be no longer effective since the 1990s, with certain stability in both agricultural management and crop genetic basis in the following years (T. Mag-
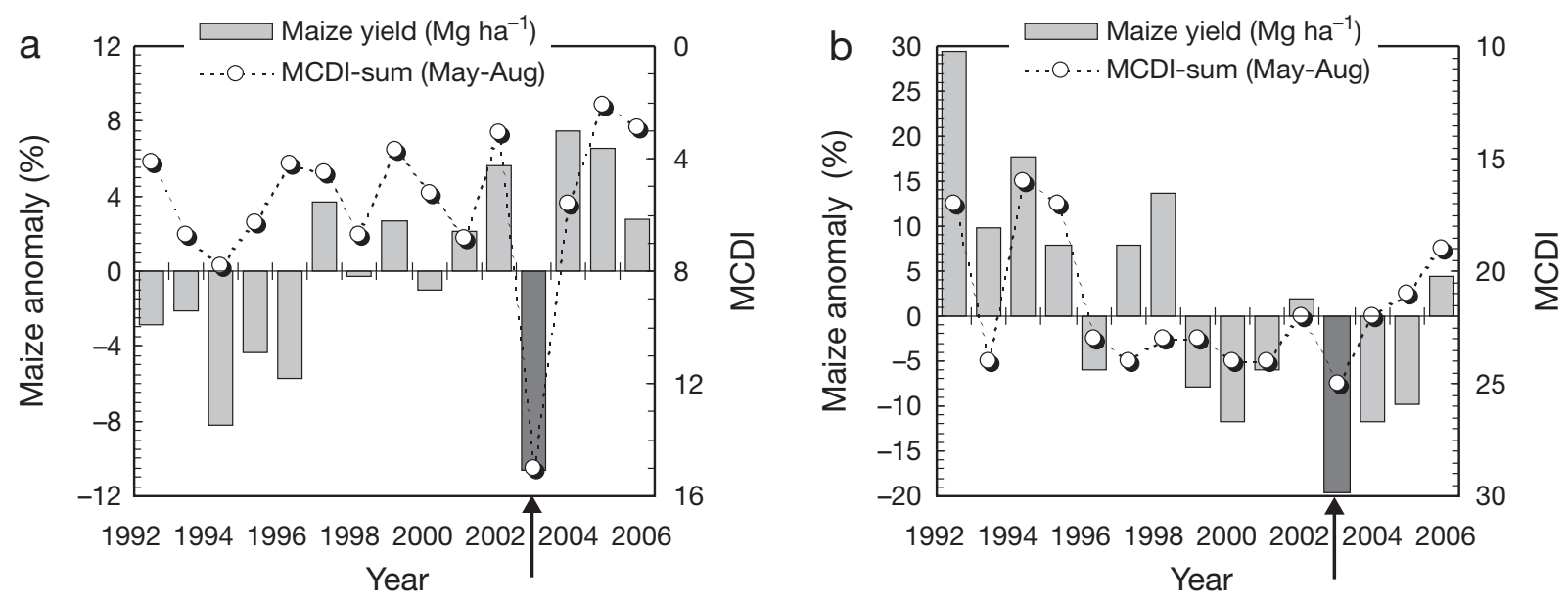

Fig. 3. Temporal patterns of maize yield percent deviation from the mean (1992 to 2006) and the Mediterranean crop drought index (MCDI) during the growing season between May and August from 1992 to 2006, (a) for the Lombardy region, north Italy, and (b) the Benevento province, south Italy. Dark bar denoted by arrow: extreme year (2003) 
giore, University of Milan, pers. comm.). This is also in reference to the strict European constraints in the sector of biotechnology (Moberg 2005), whereas genetic engineering has massively expanded worldwide and enhanced the power of modern plant breeding (Thro 2004). Thus, the observed inter-annual variation in maize yields can be considered largely driven by weather factors. Fluctuations in the stress index roughly reflect yield variations. Notably, the extreme drought of 2003 occurred with very high MCDI values and was associated with crop yield depression in both areas (dark grey bars in Fig. 3).

\subsection{Temporal pattern of drought during the maize growing season}

Temporal analysis of drought was assessed over the 4 decades from 1961 to 2000 . To examine the temporal pattern, the MCDI values for May, June, July and August were used. These months were chosen because they encompass times when plant stress may have a considerable impact on plant productivity. The yearly fluctuation of the seasonal MCDI for the relevant months is given in Fig. 4, where the values are contrasted to the season of extreme drought in 2003.

The higher values of MCDI, observed in the second half of the period considered (i.e. 1981 to 2000), are an
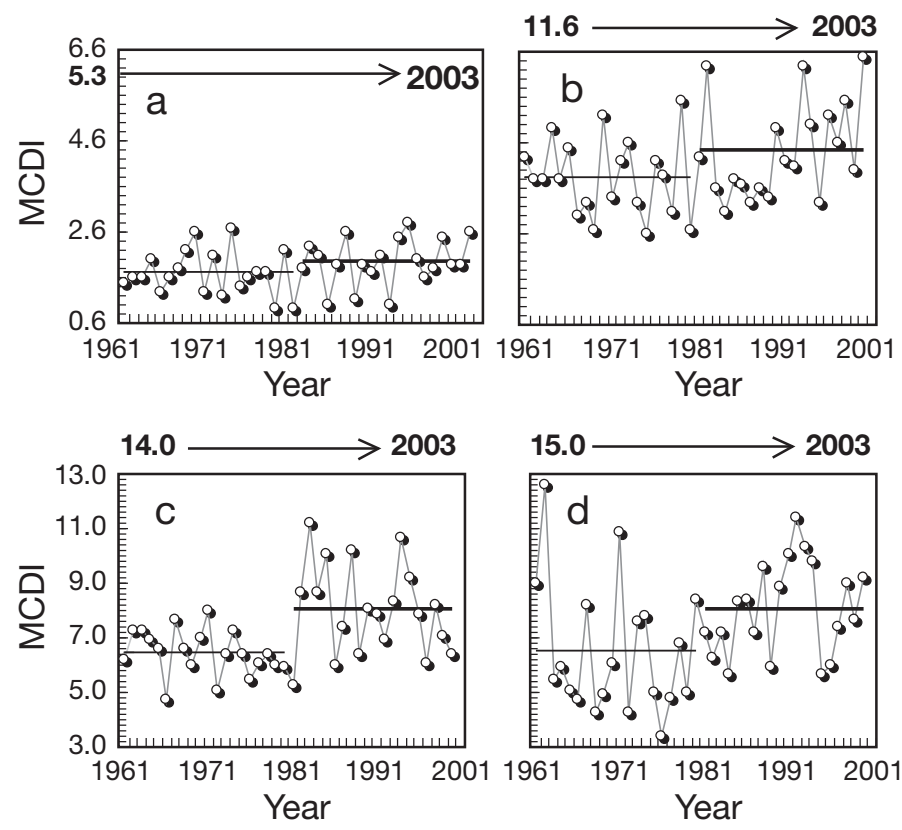

Fig. 4. Fluctuation of MCDI values in Italy from 1961 to 2000 for (a) May, (b) June, (c) July and (d) August. Mean values are reported for periods from 1961 to 1980 (thin bar) and 1981 to 2000 (thick bar). The value computed for the extreme drought in 2003 is also reported indication of the climate changes experienced in Italy over the last decades of the 20th century, which led to more severe drought conditions (Fig. 5). For the 1981 to 2000 period, a larger proportion of positive anom-
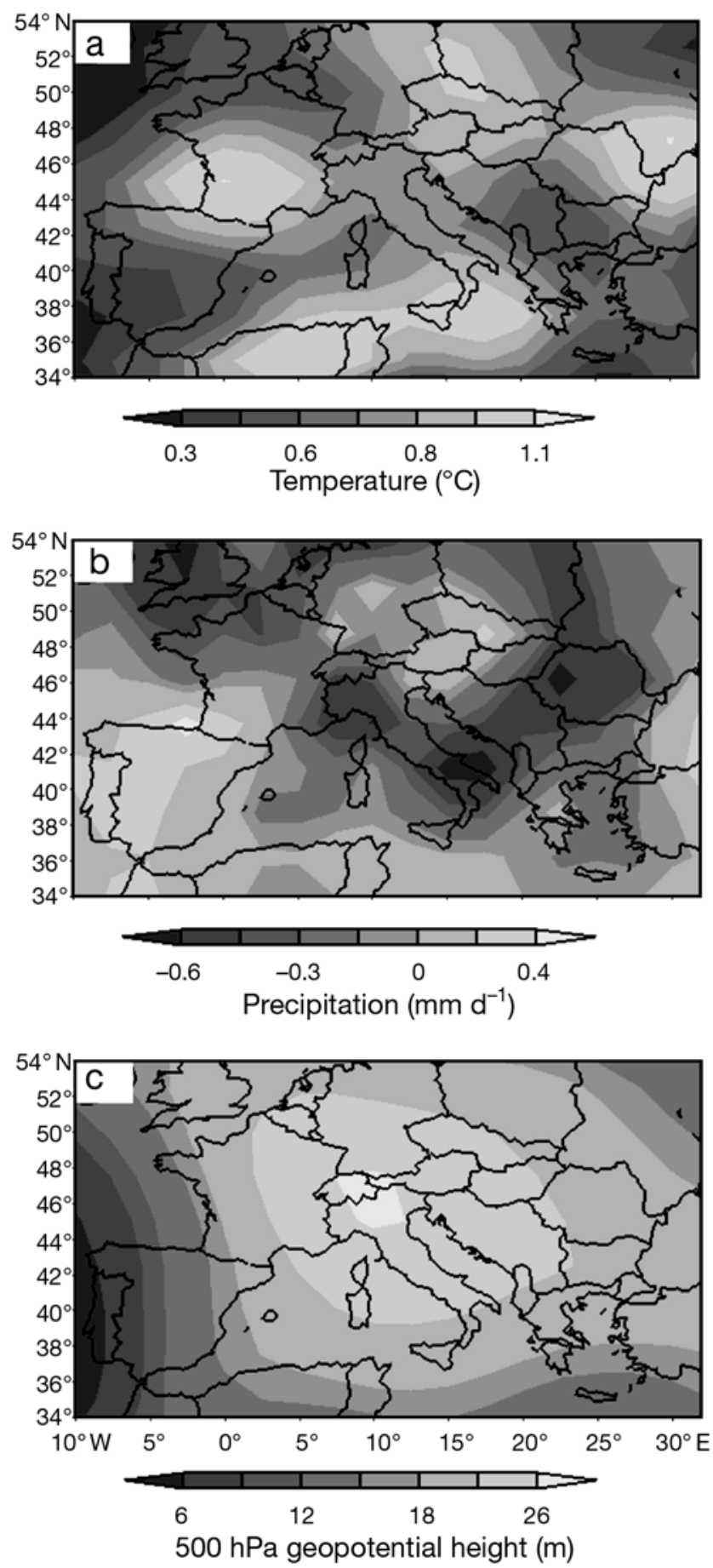

Fig. 5. Seasonal anomalies (mean of May to August: 1981 to 2000 minus 1961 to 1980$)$ of surface $(1000 \mathrm{hPa})$ (a) air temperature $\left({ }^{\circ} \mathrm{C}\right)$ and $(\mathrm{b})$ precipitation $\left(\mathrm{mm} \mathrm{d}^{-1}\right)$, and of (c) geopotential height $(\mathrm{m})$ at $500 \mathrm{hPa}$, processed by NCEP/NCAR re-analysis (source: www.cdc.noaa.gov) 
alies were observed in summer air temperature than during the 2 preceding decades (Fig. 5a), together with extended negative anomalies for precipitation (Fig. 5b). Such patterns (tendency towards air temperature increase and precipitation decrease) are roughly consistent with the geopotential anomaly distribution displayed in Fig. 5c, which shows a positive anomaly of pressure centred in northern Italy, propagating southward along the peninsula. These results are in general agreement with the conclusions obtained for other parts of Europe, where changes in the drought were related to variations in the large-scale circulation features of Europe and the Atlantic Ocean (e.g. EstebanParra et al. 1998, for decreases in precipitation over the Mediterranean and in the interior regions of Spain; Xoplaki et al. 2000, for winter dryness in Greece; Tran et al. 2002, for drought in Bulgaria). In particular, stronger westerly flows over the eastern North Atlantic and the rising $500 \mathrm{hPa}$ height (and the sea level pressure) over continental Europe during the last few decades were connected with enhanced atmospheric stabilization and anomalous advection of cold, dry air from northerly directions (Trigo et al. 2006).

The yearly percent anomalies of accumulated MCDI from May to August for 1961 to 2000 (Fig. 6a) show a distinct pattern of positive values in the second half of the period of $40 \mathrm{yr}$ investigated. Such a pattern is noteworthy for southern Italy (approaching $+40 \%$ in 1993), less marked in the centre and almost indiscernible in the north. The soil moisture pattern given for Italy during the same period (Fig. 6b) tends to reflect the MCDI anomalies. Although to a different extent, negative anomalies in soil moisture manifest themselves quite consistently across low latitudes, with attenuation toward the north (to distinctly positive values in the north, close to the Swiss border).
Examination of the MCDI data computed for different latitudinal regions (north, centre and south) also revealed important seasonal patterns (Fig. 7). In Fig. $7 \mathrm{a}-\mathrm{c}$, the average MCDI for the time interval from 1961 to 1990 is contrasted with MCDI values in 2003 within each of the regional classifications. For 2003, the MCDI was only less extreme in northern and central Italy in July. However, the co-occurrence in May to August 2003 of above normal values of MCDI within each of the regional classifications investigated demonstrates that extreme drought phenomena occurred in 2003 across all areas of Italy.

\subsection{Spatial pattern of MCDI and maize yield}

An important step in a geospatial study is the preliminary knowledge of spatial distribution of data, called exploratory data analysis. With exploratory data analysis methods, the properties of a given dataset are investigated prior to taking decisions on the kind of manipulation and computation to be carried out in further analysis (Webster 2001).

Exploratory data analysis was performed in the present study to support scaling up at the sub-regional level. Variogram functions were derived to instruct the ArcGIS-ESRI Geostatistical Analyst on how to gather and use control points during MCDI and yield interpolations with IWD. Weight $w$ (Eq. 6) was estimated for MCDI (1.42) and maize (1.65), corresponding to the lowest values of the mean prediction error and the root mean square prediction error. In the exemplary variogram surfaces of Fig. 8, geometric anisotropy can be seen in a NW-SE direction (dark grey band). Based on the above, an anisotropic neighbourhood of points was used (Fig. 8b), corresponding to the search ellipse
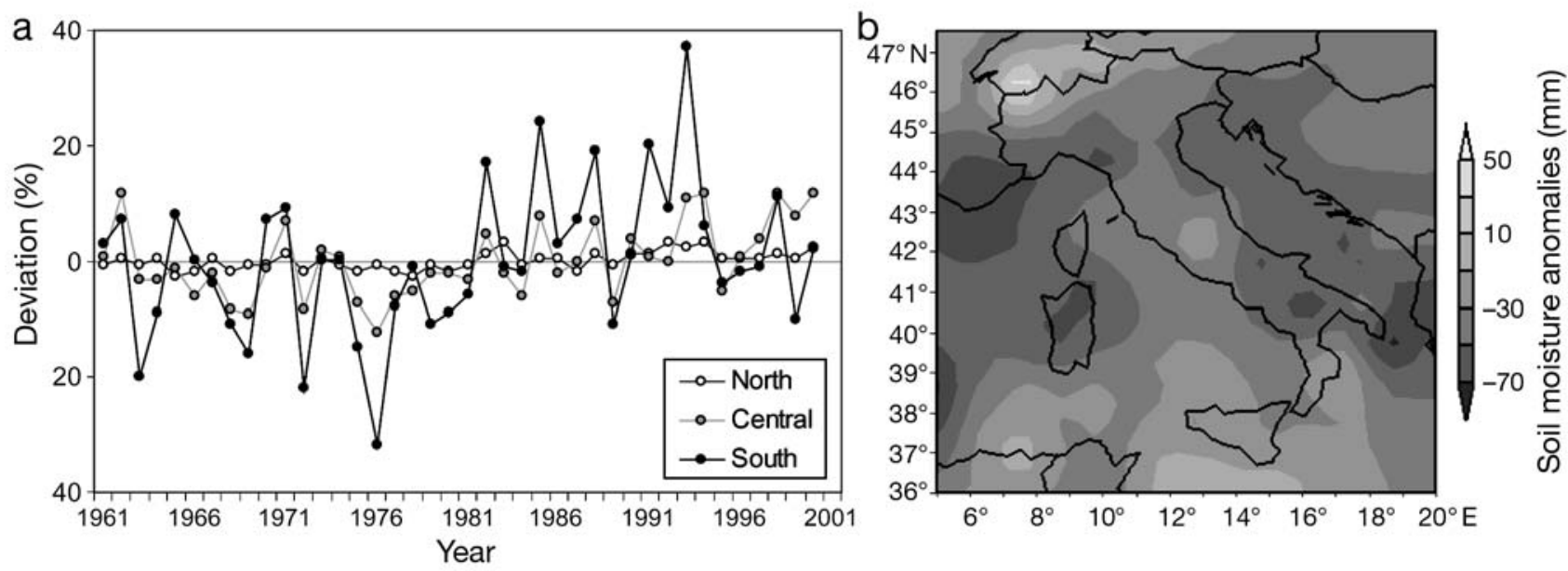

Fig. 6. (a) Percent deviations from the mean (1961 to 2000) of seasonal (from May to August) MCDI, and (b) soil moisture anomalies (mm; mean of May to August: 1981 to 2000 minus 1961 to 1980), processed by NCEP/NCAR re-analysis (source: www.cdc.noaa.gov) 

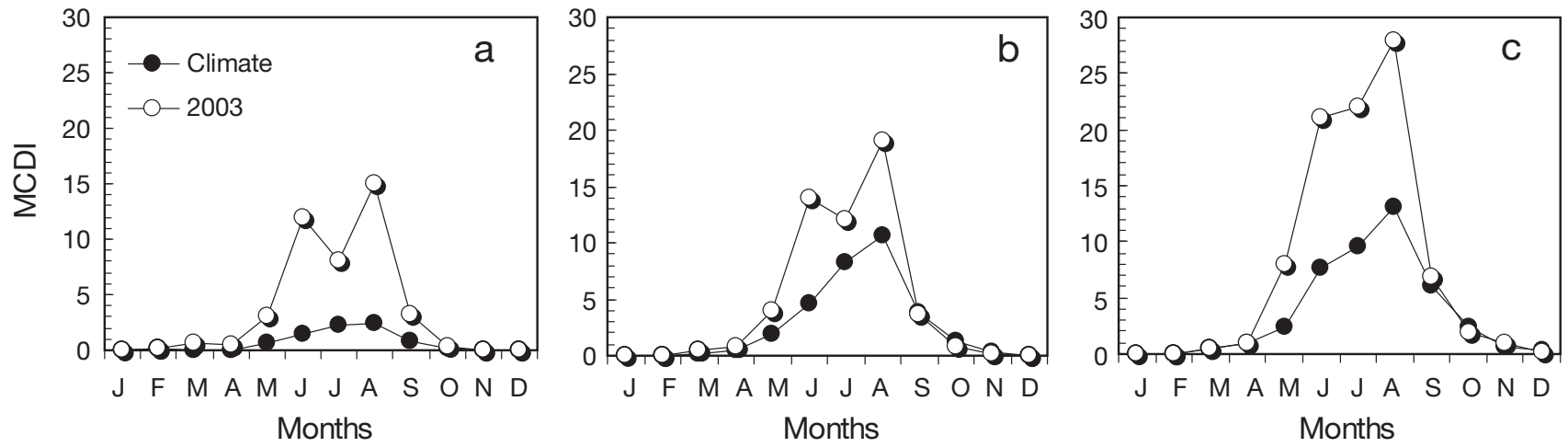

Fig. 7. Monthly regime of MCDI for 1961 to 2000 and 2003 (a to c: north to south)
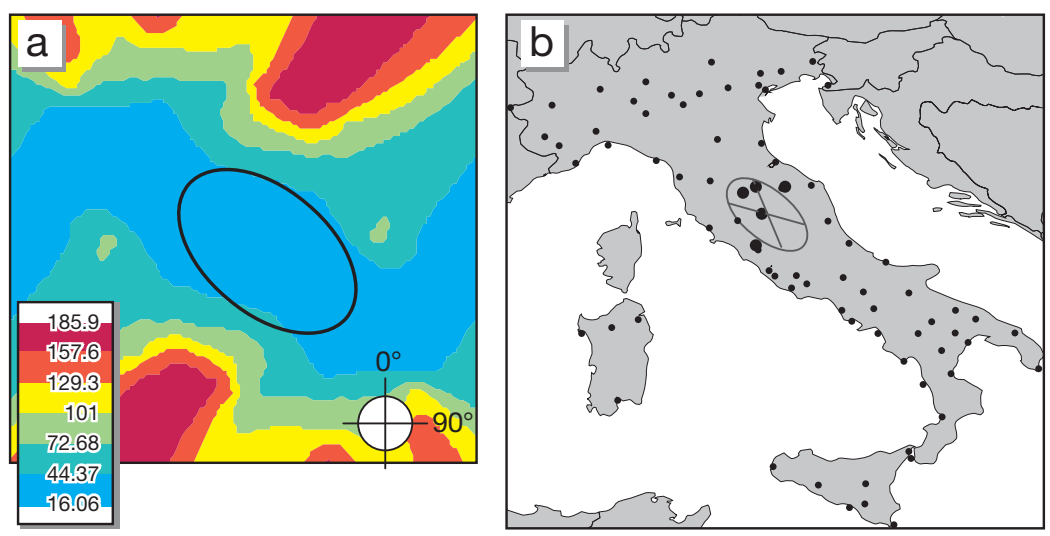

Fig. 8. (a) Variogram surface (MCDI semi-variances) with anisotropic search ellipse and (b) station pattern showing control data points for target site estimation during the interpolation process. Cross through the elipse identifies 4 sectors for station capturing

characterized by the radii of the principal axes (minimum 100000 and maximum $140000 \mathrm{~m}$ ), the angle of the major direction of anisotropy $\left(310^{\circ}\right)$, the number of sectors (4) and the number of data points (2) in each sector.

To characterize the spatial distribution of drought stress throughout the Italian region, surface grid maps of MCDI were developed based on monthly values of MCDI at each location, and 2 maps of cumulative MCDI data from May to August were produced. One of the maps shows the climatic period (Fig. 9a), and one shows the extent of MCDI values for the extreme year 2003 (Fig. 9b). Based on the climatic period, MCDI values $>50$ occurred only in insular regions (Sardinia and Sicily). However, in 2003, these values occurred in large areas of Italy, with extreme values (i.e. MCDI > 70) over the coasts of Tuscany and Latium (central and high Tyrrhenian), north Apulia (towards the Adriatic coast, $\sim 41$ to $42^{\circ} \mathrm{N}$ latitude) and major islands. These patterns were also reflected in the FAPAR map (Fig. 9c), representing August 2003 (when an increased variation in FAPAR values can be attrib- uted to the late season senescence of vegetation). A good agreement was thus achieved between areas expected to be agro-climatically drought sensitive and vegetation patterns during this extreme drought-stress event. A drought that occurs over a large region for a relatively short time period (months compared to several years), as was the case with the 2003 drought, can be economically devastating. However, the same event is not necessarily accompanied by ecological catastrophes, as illustrated by the FAPAR image (Fig. 9c).

Under normal drought stress, the agricultural sector is usually the first to be affected because of its dependence on stored soil water, which is rapidly depleted during extended dry periods. Maize is particularly sensitive to summer droughts, and this occurred in a generalized way in Italy over 2003, when this particular climatic anomaly took place. The magnitude of the difference between the $30 \mathrm{yr}$ period (1961 to 1990) and the corresponding 2003 maize yield values is illustrated spatially in Fig. 10. The following equation was used to compute the differences of Fig. 10c:

$$
\mathrm{NPD}=\frac{Y_{2003}-Y_{\text {baseline }}}{Y_{\text {baseline }}} 100
$$

where NPD (\%) is the normalized percent difference and $Y_{2003}$ and $Y_{\text {baseline }}\left(\mathrm{Mg} \mathrm{ha}^{-1}\right)$ are the mean maize yields for year 2003 and the $30 \mathrm{yr}$ period, respectively.

The contrast between the $30 \mathrm{yr}$ period and 2003 was less marked in areas such as northern Italy, the central Adriatic coast and Sicily, as a result of massive irrigation to ameliorate summer water stresses. In these areas, yields in 2003 were comparable to years when moisture was adequate for normal maize production (Fig. 10c). 

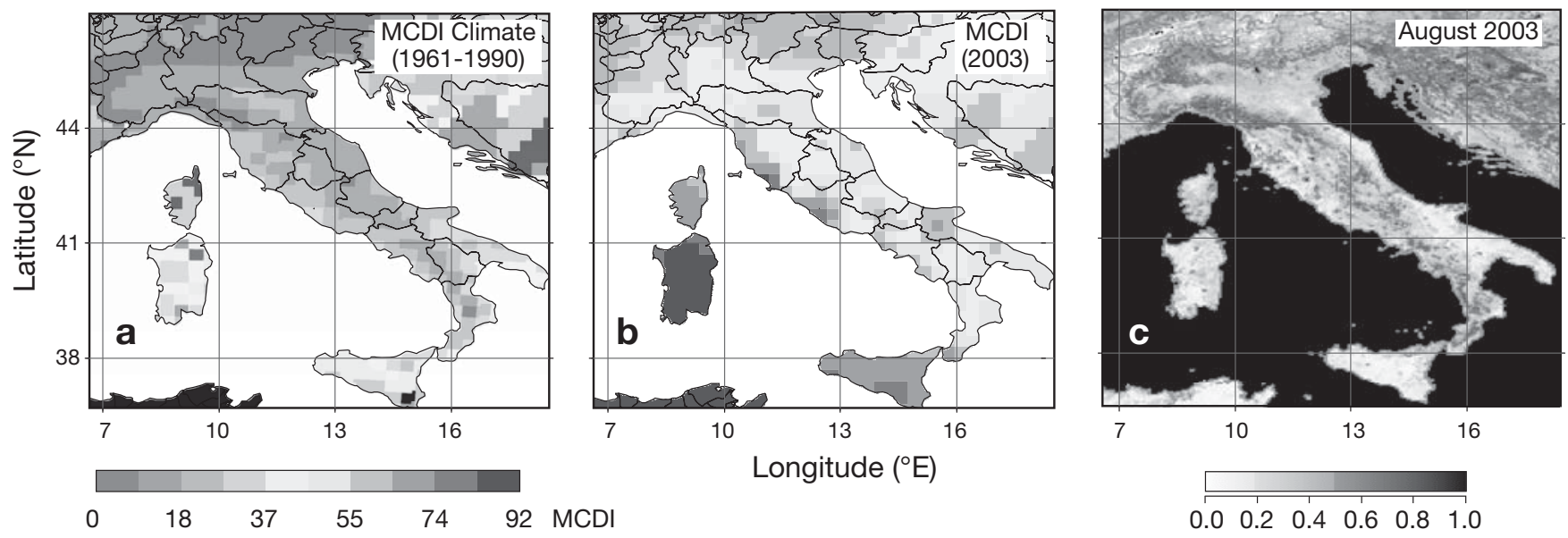

Fig. 9. (a) Spatial patterns of the summer (May to August) MCDI for the 1961 to 1990 climatic period and (b) for the extreme drought in 2003, and (c) the FAPAR (fraction of absorbed photosynthetically active radiation, available at http://fapar.jrc.it) pattern in August 2003
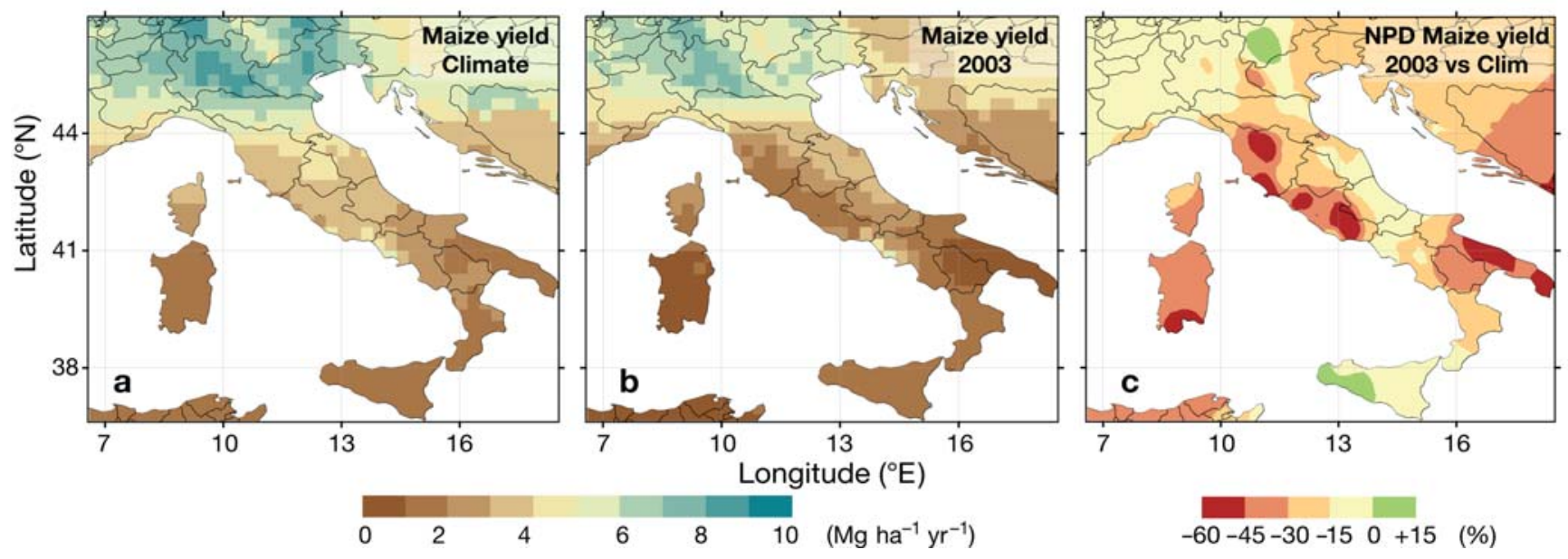

Fig. 10. Spatial patterns of (a) the average long-term (1961 to 1990) maize yield, (b) the maize yield in 2003, and (c) the maize yield by normalized percent difference (NPD) of 2003 versus long-term maize yield

\section{CONCLUSIONS}

While simulation studies are frequently published about the effects of projected future climate change on crop yields, there are relatively few studies on the impacts of the observed climate change that has already begun affecting crop production. Quantitative reconstruction of the impacts of climate change on organisms and ecosystems represents an important and challenging line of enquiry. Agricultural systems are particularly sensitive to climate changes, and historical crop yields provide an interesting proxy documentation of close interaction between environment and climate trends. The present study offers an evaluation of a newly proposed drought stress index (MCDI), which was used to quantitatively assess the distribution of drought conditions over Italy in relation to maize grain yield. The indicator proved useful in interpreting the impact of climatic changes that have occurred in Italy in the last decades of the 20th century.

For maize in Italy, it is known that the use of irrigation mitigates drought stress. This use has been (and, due to the effects of climate change, will likely continue to be) massive in certain areas of the country, with significant ecological costs (and subsequent economic costs) from depleting aquifer resources (water being a limited resource that needs to be allocated to different components of the ecosystem). Such costs, not evaluated in this study, have implications especially in situations where drought phenomena turn into a more complex climatic condition. This is a scenerio suggested by Schär et al. (2004), who have, in recent 
decades, found a pronounced increase in the year-toyear variability of the European climate in summer. Such an increase in variability might explain the unusual European summer in 2003 and may strongly affect the incidence of extreme events in the future. Furthermore, when an increasing frequency of intense rainfall events is accompanied by a clustering of dry periods, this may also represent a potentially dangerous combination for soil erosion (Sauerborn et al. 1999).

The identification of climate boundaries (areas with homogeneous climate) of drought scenarios at regional or sub-regional scales (as in this study) is important for understanding the climatic features and their potential impact on local agro-ecosystems. The results gained from the present study encourage the use of coupled GIS and geospatial techniques to develop finer interpolation surfaces or probability maps of the drought stress index. Because of the spatial and temporal variability and multiple impacts of drought, there is a need to improve the tools and data available for mapping and monitoring this phenomenon at a variety of scales.

Acknowledgements. The authors thank L. Mariani (Department of Crop Science, University of Milan) for facilitating the collection of climate and crop data used in this study and for valuable comments.

\section{LITERATURE CITED}

Alley WM (1984) The Palmer Drought Severity Index: limitations and assumptions. J Clim Appl Meteorol 23:1100-1109

Baldi M, Dalu G, Maracchi G, Pasqui M, Cesaroni F (2006) Heat waves in the Mediterranean: a local feature or a larger-scale effect? Int J Climatol 26:1477-1487

Beniston M, Stephenson DB (2004) Extreme climatic events and their evolution under changing climatic conditions. Global Planet Change 44:1-9

Briffa KR, Jones PD, Hulme M (1994) Summer moisture availability across Europe, 1892-1991: an analysis based on the Palmer Drought Severity Index. Int J Climatol 14:475-506

Bruce JP (1994) A perspective on reducing losses from natural hazards. Bull Am Meteorol Soc 75:1831-1835

Chmielewski FM, Muller A, Bruns E (2004) Climate changes and trends in phenology of fruit trees and field crops in Germany, 1961-2000. Agric For Meteorol 121:69-78

> Conedera M, Peter L, Marxer P, Forster F, Rickenmann D, Re L (2003) Consequences of forest fires on the hydrogeological response of mountain catchments: a case study of the Riale Buffaga, Ticino, Switzerland. Earth Surf Proc Land 28:117-129

- Diodato N (2007) Climatic fluctuations in southern Italy since 17th century: reconstruction with precipitation records at Benevento. Clim Change 80:411-431

Diodato N, Bellocchi G (2007) Modeling reference evapotranspiration over complex terrains from minimum climatological data. Water Resour Res 43:w05444

Easterling DR, Meehl GA, Parmesan C, Changnon SA, Karl TR, Mearns LO (2000) Climate extremes: observation, modeling and impacts. Science 289:2068-2074
Esteban-Parra MJ, Rodrigo FS, Castro-Diez Y (1998) Spatial and temporal patterns of preciptiation in Spain for the period 1880-1992. Int J Climatol 18:1557-1574

Fowler HJ, Kilsby CG (2002) A weather-type approach to analysing water resource drought in the Yorkshire region from 1881 to 1998. J Hydrol 262:177-192

Füssel HM, van Minnen JG (2001) Climate impact response functions for terrestrial ecosystems. Integrated Assess 2: 183-197

Gage SH (2003) Climate variability in the North Central Region: characterizing drought severity patterns. In: Greenland D, Goodin DG, Smith RC (eds) Climate variability and ecosystem responses at long-term ecological research site. Oxford University Press, Oxford, p 56-73

Gage SH, Mukerji MK (1977) A perspective of grasshopper population distribution in Saskatchewan and interrelationships with weather. Environ Entomol 6:469-479

Gathara ST, Gringof LG, Mersha E, Sinha Ray KC, Spasov P (2002) Report of the CAgM working group on the impacts of desertification and drought and of other extreme meteorological events. WMO-Commission for Agricultural Meteorology, Geneva

Ghosh TK (1997) Investigation of drought through digital analysis of satellite data and geographical information systems. Theor Appl Climatol 58:105-112

Hisdal H, Stahl K, Tallaksen LM, Demuth S (2001) Have streamflow droughts in Europe become more severe or frequent? Int J Climatol 21:317-333

Johnston K, ver Hoef JM, Krivoruchko K, Lucas N (2001) Using ArcGis geostatistical analyst. ESRI Press, New York

Lloyd-Hughes B, Saunders MA (2002) A drought climatology for Europe. Int J Climatol 22:1571-1592

Lobell DB, Asner GP (2003) Climate and management contributions to recent trends in US agricultural yields. Science 299:1032

Loomis RS, Connor DJ (1992) Crop ecology: productivity and management in agricultural systems. Cambridge University Press

Luterbacher J, Dietrich D, Xoplaki E, Grosjean M, Wanner H (2004) European seasonal and annual temperature variability, trends, and extremes since 1500. Science 303: 1499-1503

Masson-Delmotte V, Raffalli-Delerce G, Danis PA, Yiou P and others (2005) Changes in European precipitation seasonality and in drought frequencies revealed by a fourcentury-long tree-ring isotopic record from Brittany, western France. Clim Dyn 24:57-69

Mavromatis T (2007) Drought index evaluation for assessing future wheat production in Greece. Int J Climatol 27: 911-924

Meir P, Cox P, Grace J (2006) The influence of terrestrial ecosystems on climate. Trends Ecol Evol 21:254-260

Meneguzzo F, Giarola S, Grippa G, Gozzini B (1996) Mesoscale operational rainfall forecasts in north-western Tuscany. Boll Geofisico 19:39-55

Min SK, Kwon WT, Park EH, Choi Y (2003) Spatial and temporal comparisons of droughts over Korea with East Asia. Int J Climatol 23:223-233

Moberg S (2005) Implications for European seed industry and the agro value chain. In: Seminar on plants for the future. Norwegian University of Life Sciences and Norwegian Bioindustry Association, Oslo (available at www.biotekforum.no)

Modarres R (2007) Streamflow drought time series forecasting. Stoch Environ Res Risk Assess 21:223-233

New M, Todd M, Hulme M, Jones P (2002) Precipitation measurements and trends in the twentieth century. Int $\mathrm{J}$ 
Climatol 21:1899-1922

Olesen JE, Bindi M (2002) Consequences of climate change for European agricultural productivity, land use and policy. Eur J Agron 16:239-262

Palmer W (1965) Meteorological drought. Res. Paper No. 45, US Weather Bureau, Washington, DC

Pauling A, Paeth H (2006) On the variability of return periods of European winter precipitation extremes over the last five centuries. Clim Past Discuss 2:157-189

Perini L, Beltrano MC (2004) Italian agricultural production and the heat wave during summer 2003. Italian Ministry of Agriculture, Rome

Perini L, Beltrano MC, Dal Monte G, Stanislao E and others (2004) Atlante agroclimatico, agroclimatologia, pedologia, fenologia del territorio italiano. Climagri Project, Research line 2.1, UCEA, Rome

Rebetez M, Mayer H, Dupont O, Schindler D, Gartner K, Kropp J, Menzel A (2006) Heat and drought 2003 in Europe: a climate synthesis. Ann For Sci 63:569-577

Sauerborn P, Klein A, Botschek J, Skowronek A (1999) Future rainfall erosivity derived from large-scale climate models - methods and scenarios for a humid region. Geoderma 93:269-276

Schär C, Vidale PL, Lüthi D, Frel C, Häberll C, Liniger MA, Appenzeller C (2004) The role of increasing temperature varibility in European summer heatwaves. Nature 427: 332-336

Snyder RL (2002) Degree days. In: Rossi F, Duce P, Spano D (eds) Advanced short course on agricultural, forest and micro-meteorology. CNR - Institute of Biometeorology, Florence, p 268-281

Klein Tank AMG, Konnen GP (2003) Trends in indices of daily temperature and precipitation extremes in Europe, 1946-99. J Clim 16:3665-3680

Tao F, Yokozawa M, Xu Y, Hayashi Y, Zhang Z (2006) Climate changes and trends in phenology and yields of field

Editorial responsibility: Mikhail Semenov,

Harpenden, UK crops in China, 1981-2000. Agric For Meteorol 138:82-92

Thomsen R (1993) Future drought, water shortages in parts of western Europe. Eos 74:161-176

Thro AM (2004) Europe on transgenic crops: how public plant breeding and eco-transgenics can help in the transatlantic debate. AgBioForum 7:142-148

Tran LT, Knight CG, Wesner V (2002) Drought in Bulgaria and atmospheric synoptic conditions over Europe. GeoJournal 57:149-157

Trigo R, Xoplaki E, Zorita E, Luterbacher J and others (2006) Relations between variability in the Mediterranean region and mid-latitude variability. In: Lionello $\mathrm{P}$, MalanotteRizzoli P, Boscolo R (eds) Mediterranean climate variability. Elsevier, Amsterdam, p 179-206

Vicente-Serrano SM, González-Hidalgo JC, de Luis M, Raventós J (2004) Drought patterns in the Mediterranean area: the Valencia region (eastern Spain). Clim Res 26:5-15

Vogt JV, Niemeyer S, Somma F, Beaudin I, Viau AA (2000) Drought monitoring from space. In: Vogt JV, Somma F (eds) Drought and drought mitigation in Europe. Kluwer Academic, Dordrecht, p 167-183

Webster R (2001) Statistics to support soil research and their presentation. Eur J Soil Sci 52:331-340

Wilhelmi OV, Hubbard KG, Wilhite DA (2002) Spatial representation of agroclimatology in a study of agricultural drought. Int J Climatol 22:1399-1414

Wilhite DA (2000) Drought as a natural hazard: concepts and definitions. In: Wilhite D (ed) Drought: a global assessment, Vol 1. Routledge, London, p 3-18

Wu H, Wilhite DA (2004) An operational agricultural drought risk assessment model for Nebraska, USA. Nat Hazards 33:1-21

Xoplaki E, Luterbacher J, Burkard R, Patrikas I, Maheras P (2000) Connection between the large scale $500 \mathrm{hPa}$ geopotential height fields and precipitation over Greece during winter time. Clim Res 14:129-146

Submitted: July 5, 2007; Accepted: November 26, 2007 Proofs received from author(s): February 14, 2008 